\title{
Building the case for a National Outcomes Fund
}

\author{
Sarah Doyle* and Dale McFee ${ }^{\dagger}$
}

\begin{abstract}
This paper argues for the creation of a National Outcomes Fund as a critical element of a "social impact economy" that appropriately values and diverts resources to social good. This initiative would make funds available contingent on the achievement of targeted outcomes in priority policy areas. It would invite service providers, alongside ministries or other agencies from any order of government, to propose innovative solutions, with the dual objective of improving outcomes for individuals and communities and improving value for public money - which in some cases will correspond with a net decrease in government expenditures over time. It addresses policy recommendations primarily to the federal government, as well as to provincial, territorial, and municipal governments.
\end{abstract}

Key Words Social impact; social innovation; policy innovation; impact investing; social finance; outcomes-based funding; pay-for-success; Social Impact Bond.

Journal of CSWB. 2017 Mar;2(1):22-28

www.journalcswb.ca

\section{INTRODUCTION}

Governments spend billions on a wide array of social services, many of which are delivered by non-profit organizations, but often lack information on the impact of these services. This is concerning from a value for public money perspective. It also signals a potentially massive missed opportunity to focus resources on delivering systemic change-change that takes people out of poverty and off the streets, helps them find sustainable employment, prevents crime, and reduces the incidence of chronic disease. These challenges, in the meantime, carry a significant human, social, and financial cost.

This is particularly pressing in the context of an aging population that is shifting from net contributors to net beneficiaries of public services, leading to growing government expenditures and declining revenues. Reducing demand for services, while at the same time improving the wellbeing of individuals and communities, is one way to bend the expenditure curve.

To realize this change, governments need to extend their gaze beyond the cycle of funding services to meet immediate needs, to include the long game of reinventing the status quo. This will demand new forms of collaboration within government and across sectors, new sources of capital, and new approaches to managing risk. It will also require the use of data to drive performance, measure the collective impact of services, and build evidence on what works.

A new model for linking these attributes has emerged in recent years. In outcomes-based funding agreements, governments agree to pay for an intervention only if preagreed, measurable outcomes are achieved. The working capital needed to deliver the intervention is either provided by the service provider, or raised from a growing cadre of impact investors who are interested in linking social and financial returns.

This paper recommends a $\$ 100 \mathrm{M}$ Government of Canada Outcomes Fund. It uses the example of homelessness and mental health to describe the opportunity; however, this fund could help to improve outcomes across a wide range of policy priorities, from youth unemployment to chronic disease.

\section{The Need for Change: Challenges Associated with Current Funding Models}

Governments operate according to accountability frameworks and time horizons that do not correspond to the size and shape of social challenges.

The public sector is governed by a system of accountability that is unduly focused on the simpler question of where money is going rather than on what it is achieving. As a result, accountability frameworks tend to focus on activities and outputs more than outcomes-for example, measuring the number of people that attended an employment program (activity-based) rather than measuring sustainable employment or duration of employment (outcome-focused). In the same manner, governments tend to measure expenditures versus savings or cost avoidance associated with improved outcomes. The reporting burden on service providers is often high and rarely provides insight to support performance management. In 2006, the Independent Blue Ribbon 
Panel on Grant and Contribution Programs concluded that there was a significant need for reform to simplify reporting requirements while improving accountability for results and encouraging innovation. According to the Panel's final report, which remains relevant, the aim of accountability frameworks should not be "to eliminate errors but to achieve results, and that requires a sensible regime of risk management and performance reporting" (Clark \& Lankin, 2006).

Timelines are a challenge. While marginal reforms have been made to, for example, increase the use of multi-year funding agreements, governments tend to fund services on a short-term and small-scale basis that restricts the ability of service providers to engage in strategic planning, cover core costs, experiment, measure impact, or scale up effective services (S. Doyle, personal communication, August 17, 2016; Clark \& Lankin, 2006). Even where a new approach is tested, the accountability structure of government is out of step with the timeline of innovation, leading to pilots that are not evaluated with a view to scaling what works (S. Doyle, personal communication, August 17, 2016).

Accountability risk tends to concentrate around changes to existing programs. There is far more political and professional risk in trying something new than there is in continuing to fund the same services.

Moreover, ministers are responsible for reporting on the funding programs run by their individual ministries, even though the challenges that these programs are meant to address cut across ministerial mandates. These silos are often replicated at the service provider level, and are reinforced by one-way reporting requirements and privacy rules that restrict information gathered by one ministry from being shared with others. From a client perspective, this means a fragmented and inefficient landscape of services (Mental Health Commission, 2013a). It also limits understanding of the collective impact of public expenditures.

These challenges call for a focal shift from activities and outputs to outcomes. This shift would demand approaches to service design and impact measurement that are clientcentred and data-driven.

\section{The Need for Change: the Example of Homelessness and Mental Health}

The shortcomings of public funding, accountability and incentive structures are leading to a sub-optimal allocation of public resources and missed opportunities for improving the lives of Canadians. This is alarmingly apparent in the area of homelessness.

In Canada, over 200,000 people are homeless each year. Up to 67 per cent of these people report mental health issues, which can both contribute to and be aggravated by poverty and homelessness, and tend to negatively impact an individual's ability to seek care (Goering, Veldhuizen \& Watson et al., 2014).

These challenges represent a significant public cost burden. Homelessness has been estimated to cost Canadians \$7B each year, related to hospital stays, emergency room visits, interactions with police and courts, jail/prison incarcerations, emergency shelter, welfare and disability income, and community services (Gaetz, Dej, Richter et al., 2014). This amount is even higher when the cost of underutilized human capital is taken into account. The broader cost of mental health issues has been conservatively estimated at about $\$ 50 \mathrm{~B}$ per year, and this figure is expected to rise (Smetanin, Stiff, Briante et al., 2011; Mental Health Commission, 2013b). A growing body of literature suggests that interventions that improve mental health outcomes yield a net economic benefit (Chisholm, Sweeny, Sheehan et al., 2016).

There is no lack of evidence-based solutions in the area of homelessness. Notably, the At Home/Chez Soi randomized controlled trial showed that the Housing First (HF) model, which provides stable housing complemented by wrap-around supports tailored to local contexts and individual needs, improves outcomes related to housing stability, quality of life, community functioning, substance use, and mental health symptoms. It also demonstrated that for every $\$ 10$ invested in HF services, average savings after two years ranged from $\$ 3.42$ for individuals with moderate needs all the way to $\$ 21.72$ for the 10 per cent of participants who represented the highest cost burden at the inception of the study (Mental Health Commission, 2013a). Even where savings are not expected, shifting costs away from crisis services will result in greater system efficiency and, most importantly, will focus resources on improving the lives of disadvantaged individuals and communities.

Replication of the HF model across Canada has, however, been slow. That lag is an example of the structural challenges described above, which are limiting the systemic adoption of client-centred and data-driven approaches to improving outcomes for Canadians grappling with homelessness, mental health, and other challenges.

\section{A New Model for Improving Outcomes}

New models are emerging that focus attention on outcomes. These range from adopting human wellbeing measures alongside Gross Domestic Product, to introducing "community hub" (or situation) tables-which have become widespread in Saskatchewan and Ontario as a means to bring different ministries and service providers together to address composite risk factors of individuals and families requiring multiple, coordinated supports (Canadian Police College, 2014).

This paper focuses on a relatively new model - an outcomes-based funding (or pay-for-success) agreement in which governments commit to pay for specific, measureable outcomes. ${ }^{1}$ For service providers, this model provides greater flexibility to adapt service design midway through implementation based on new information, without having to renegotiate grant or contribution terms, which is particularly valuable for services seeking to address complex challenges. It also means more efficient reporting focused on outcomes versus activities and outputs, as well as investment in robust data capture and evaluation.

In most cases, service providers would struggle to absorb financial risk due to limited cash flow flexibility and reserves. Increasingly, though, there is a new cadre of impact investors interested in doing good with their money. A growing number of outcomes-based funding agreements around the world are engaging these investors to provide the up-front funding needed to implement a project (Dear, Helbitz, Khare

These agreements could take multiple forms, including contracts, grant agreements and contribution agreements. 
et al., 2016). In this model, sometimes called a Social Impact Bond, investors receive a return that is dependent on the level of success achieved (see Figure 1).

Importantly, program design, target outcomes and performance management frameworks are established in the up-front agreements through a collaborative process, which must engage service providers as equal partners to ensure that agreements reflect what is best for the clients being served.

These models improve value for money from a government perspective, given that the risk of failure is transferred to investors or service providers. Government funders are willing to pay a return because of this risk transfer, which means that they do not pay if outcome targets are not met. After agreements are signed, governments would have a very limited role-with no activities or outputs oversight. In general, this model is suited to preventative approaches that aim to improve individual or cohort outcomes, often diverting individuals from reliance on institutional or crisis services. It is not intended to replace services provided by public bodies according to a statutory duty.

This model requires partners to agree on target outcomes, a measurement approach, and prices associated with outcomes, and to ensure that the infrastructure for data collection and analysis is in place. Impact measurement methodologies can take a range of forms, from baseline study comparisons to randomized controlled trials. The ease of defining and measuring success varies by issue area. In the areas of homelessness and mental health, for example, metrics could relate to some combination of stable housing, reduced crisis intervention use, and wellbeing indicators. The MaRS Centre for Impact Investing published a Housing First Social
Impact Bond Feasibility Study in 2014, which detailed a range of potential approaches for funding HF supports on an outcomes basis (Miguel \& Abughannam, 2014).

Third-party evaluations of the outcomes-based funding model are starting to emerge which suggest that, despite relatively high transaction costs, this model leads to more thoughtful and rigorous data capture and analysis, more effective performance management, and better results than would have been possible under more traditional funding models (Department for Work and Pensions, Gov. of Great Britain, 2014; Tan, Fraser, Glacomantonio et al., 2015).

According to an evaluation of the UK's youth-focused Innovation Fund, the "[Social Impact Bond] funding model has been a key driver of behaviours and has focused attention on generating starts [intake of program participants] and tracking individual participants towards the achievement of outcomes" (Department for Work and Pensions, 2014).

Outcomes-based funding can help governments circumvent the structural barriers described above, by transferring implementation risk to investors and introducing an accountability framework focused on outcomes, which necessitates the use of data to improve performance and understand impact, and pulls funding out of traditional ministry silos, jurisdictional boundaries, and budget timelines. Implementation of this model in Canada has been limited so far, at least partially because this circumvention of traditional structures requires new vehicles to be established.

Proposal: a National Outcomes Fund

This paper recommends that the Government of Canada launch a $\$ 100 \mathrm{M}$ National Outcomes Fund. The proposed fund would provide a vehicle for all orders of government to adopt

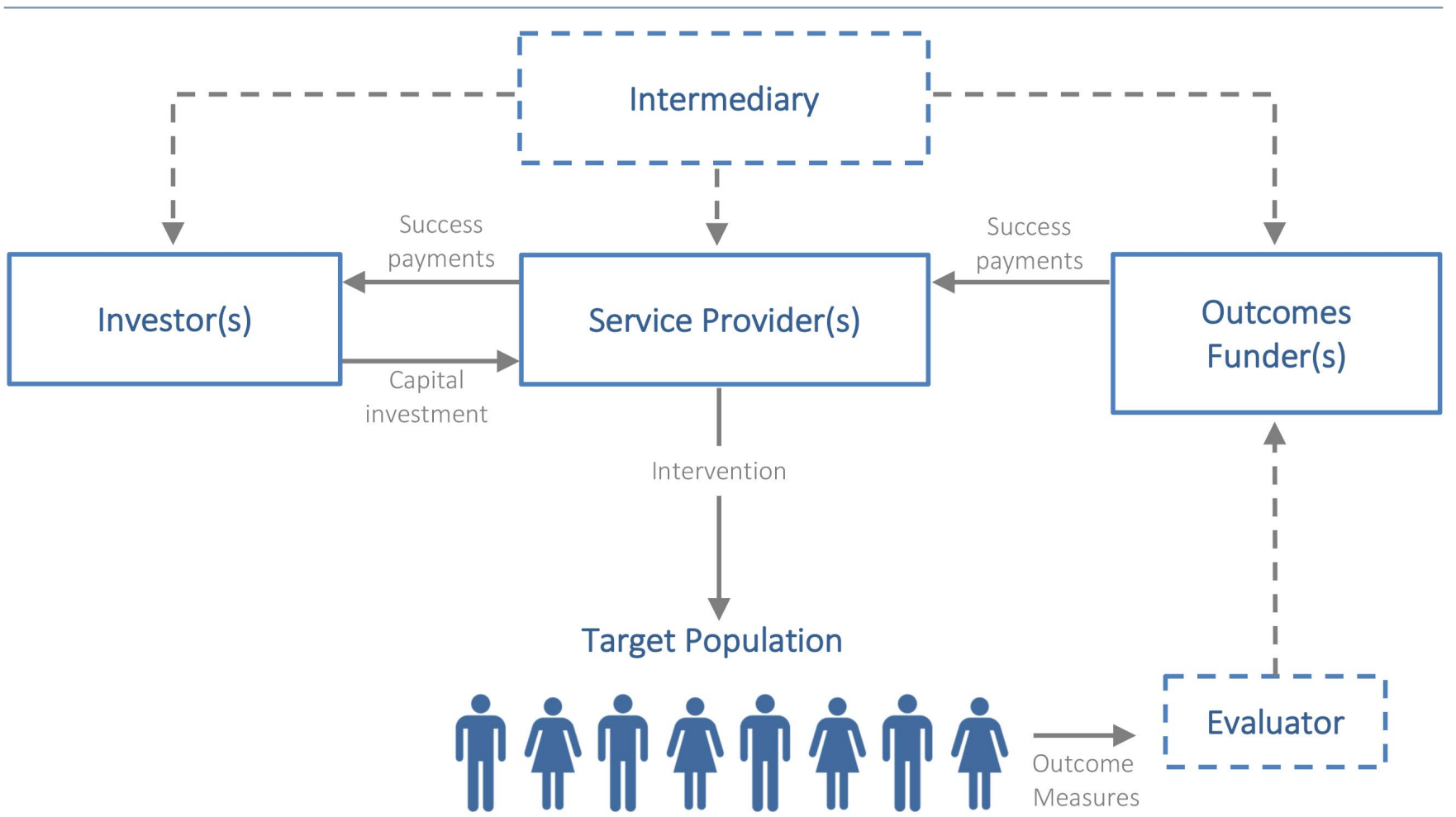

FIGURE 1 Diagram of a Social Impact Bond. 
outcomes-based funding approaches by offering matching funds to federal, provincial, and territorial ministries and local governments. This would help to ensure that the government bodies ultimately responsible for determining whether to take a project to scale are owning the experiment from the beginning. It would also address the disincentive for any one ministry to pay for a project whose benefits, including any savings, would accrue to multiple ministries or orders of government. The Fund could pay for outcomes unilaterally where a pilot demonstration project has particular value.

The proposed fund would support projects aiming to improve outcomes in priority policy areas, with a focus on those that reflect the collective impact of multiple ministries, governments, and service providers. Target outcomes would be described at a high level, allowing flexibility for service providers and sponsoring government bodies to propose specific metrics. These could include outcomes related to, for example, stable housing and mental health, training and employment for Canadians facing labor market barriers, crime prevention, and reducing the incidence of chronic disease.

The proposed fund (depicted in Figure 2) would:

1. Pay for outcomes. Service providers and government bodies would be invited to bid for outcomes-based funding through a competitive application process. The bidding timeframe would be long enough to allow new partnerships to form between service providers whose collective impact is likely to be greater, and between service providers and government sponsors.

2. Promote the transformative potential of outcomes-based funding. The Fund would partner with expert intermediaries to help service providers, governments, and other partners structure project proposals that are suited to an outcomes-based approach.

3. Ensure access to capacity building support. Applicants with promising proposals at an initial expression of interest stage would be eligible for technical and capacity building support to further develop their proposals. This support, provided by intermediaries, should include assistance with defining target outcomes, metrics and evaluation strategies, financial modelling, agreement negotiation, investor engagement, and legal advice.

4. Capture and share lessons. In addition to the evaluations required to verify outcomes for each project, an evaluation of the impact of the Fund would be conducted in at least two phases (e.g., two years after launch and one year following the close of the longest-running project). All intellectual property would be made publically available to facilitate the development of best practices and foster efficiencies, for example, through the use of common templates. Access to data will be a critical success factor. The National Outcomes Fund could be used to pilot data strategies that enable datasets from different

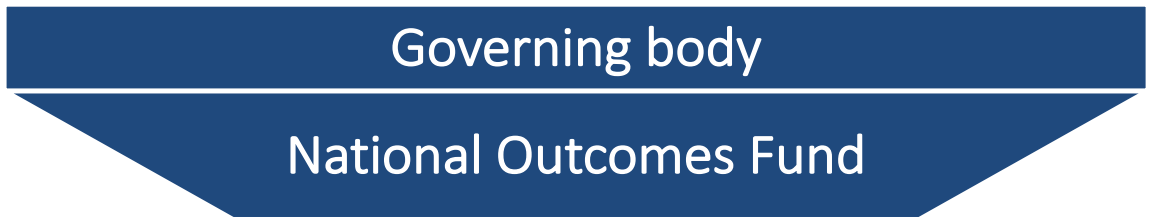

Outcome A

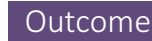

B
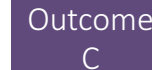

Outcome D

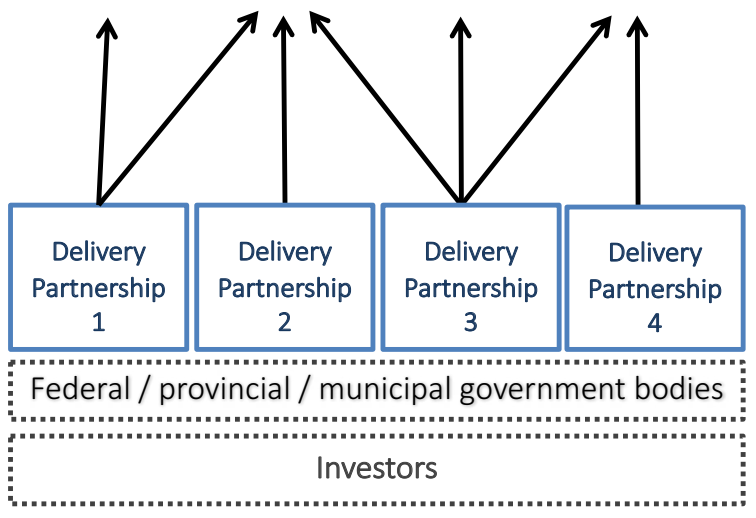

Technical and capacity building support

Data collection and analysis, performance management

Independent evaluator
- Provides strategic direction and oversight of fund activities

- Established by the Government of Canada and centrally managed (e.g., by PCO)

- Priority outcomes are identified

- Proposals are solicited on a competitive, rolling basis, to identify interventions with strong potential to achieve one or more target outcomes

- Service providers may apply: - Independently or in partnership

- With or without outcomes funding commitments from other government bodies

- With or without investors

- Fund provides access to expert support to refine proposals

- Data and performance management strategies enable adaptive implementation

- An evaluator is required to verify outcomes

FIGURE 2 National Outcomes Fund. PCO = Privy Council Office 
TABLE I Examples of Outcomes Funds

\begin{tabular}{|c|c|}
\hline Name & Description \\
\hline $\begin{array}{l}\text { UK Department } \\
\text { for Work and } \\
\text { Pensions (DWP) } \\
\text { Innovation Fund }\end{array}$ & $\begin{array}{l}\text { This } £ 30 \mathrm{M} \text { fund ran from } 2012 \text { to } 2015 \text {, funding } 10 \text { Social Impact Bonds (SIBs). Its objectives were to improve } \\
\text { education, training and employment outcomes for disadvantaged youth and those at risk of disadvantage, } \\
\text { improve the evidence base for effective approaches, and assess the savings generated. It used a competitive } \\
\text { bidding process based on a rate card listing target outcomes and maximum prices the department was willing } \\
\text { to pay for each. Prices were set based on a review of available data on service costs and estimates of the value } \\
\text { of target outcomes and were intended to be indicative. Bidders were invited to identify one or more outcomes } \\
\text { from this list that they would work to achieve, and their price per outcome under the maximum cap. The bidding } \\
\text { process was staged, with a second application round providing time for new partnerships to form between service } \\
\text { providers whose collective impact was likely to be greater, and who might otherwise have competed for scarce } \\
\text { funds. Evaluation was based on a matched area comparison counterfactual group. Funded projects have reached } \\
\text { completion, achieving target outcomes and in some cases leading to follow-on funding. While broadly successful, } \\
\text { the three-year program time frame made it challenging to provide youth with complex needs who were already } \\
\text { not in education, employment or training with the more resource intensive and longer-term support needed to } \\
\text { significantly improve their outcomes, compared, for example, with younger at-risk populations (Department for } \\
\text { Work and Pensions, 2014; HM Government, 2016). }\end{array}$ \\
\hline
\end{tabular}

UK Fair Chance Fund

Social Outcomes Fund

Commissioning Better Outcomes Fund

Australian Try, Test and Learn Fund

US Social Innovation Fund
This £15M fund, launched in 2014, has provided outcomes funding for seven SIBs aimed at improving housing, education, and employment outcomes for about 16,000 homeless youth with more complex needs due, for example, to mental health issues, substance misuse, or previous interactions with the criminal justice system. More specifically, outcome targets include: stable housing for 3, 6, 12 and 18 months; achievement of National Vocational Qualifications or equivalent; sustained volunteering; and full or part-time work for 6-26 weeks. Outcomes are measured on an individual basis, with no comparison group. These SIBs are funding non-profit service providers to implement innovative, relatively untested programs and to measure what works. Over $£ 5 \mathrm{M}$ in capital has been raised so far (Cabinet Office, Government of Great Britain [Press Release], 2014; Dear et al. 2016; Cabinet Office and Department for Communities and Local Government, 2014a\&b).

The UK Cabinet Office is also managing a £20M fund that provides top-up funding to SIBs or other projects funded on an outcomes basis, in recognition of the government silos that disincentivize each from paying for projects whose benefits and resulting savings will accrue to multiple ministries, agencies or levels of government. It privileges projects that are likely to result in public sector savings (Big Lottery Fund, 2016; Cabinet Office, 2013; Cabinet Office, 2016b).

This $£ 40 M$ fund, managed by the Big Lottery Fund, is operated in collaboration with the Social Outcomes Fund. It pays for outcomes and provides technical support to develop promising proposals. Both funds are focused on complex and expensive social challenges.

This $\$ 96.1 \mathrm{M}$ fund is expected to run for four years, starting in 2016-17, to support the testing of new approaches to reducing long-term welfare dependency by comparing outcomes in an intervention group with outcomes in a control group. It will target groups identified as being at high risk of long-term welfare dependency by the Australian Priority Investment Approach to Welfare initiative, which used actuarial valuation and predictive analytics to identify risk factors and estimate future costs. The Australian government will continue to fund programs that are shown to be effective, and will discontinue funding to those that are not. SIBs may be one of the tools used, but this fund will not operate exclusively on the basis of payments contingent on success. This model has been used in New Zealand since 2011, but has been criticized for focusing too heavily on near-term outcomes such as improved job placement rates as well as cost savings, with the implication that "success" may not take into account stable employment or wellbeing, and that individuals who require support but do not represent the highest cost burden may receive less attention. It is not yet clear what outcomes the Australian fund will focus on, but some stakeholders have called for the inclusion of broader and longer-term outcomes, such as stable employment, skills development, and health outcomes (Treasurer, Government of Australia, 2016a\&b; Department of Social Services, Gov. of Australia, 2016; Carp, 2016).

This fund, managed by the Corporation for National and Community Service, was set up to provide longer-term, larger-scale funding through community partnerships with a strong emphasis on evaluating results. It has funded 58 studies assessing the feasibility of outcomes-based funding projects and is now supporting nine of these through the agreement structuring phase (Office of Social Innovation and Civic Participation, Gov. of U.S.A., 2016; Munoz \& Donovan, 2016). 
ministries, orders of government, and service providers to be shared, merged and analyzed.

Canada's Fund would build on international best practices, such as the UK Cabinet Office £80M Life Chances Fund, which will subsidize local government commitments to pay for outcomes associated with the most complex social challenges. The Life Chances Fund will contribute about 20 per cent of total outcomes funding to projects commissioned by local governments. It will issue several calls for proposals around themes such as drug and alcohol dependency, children's services, disadvantaged young people, early childhood interventions, health, and services for seniors. The nine-year timeframe will support projects with different start dates and timeframes for measuring outcomes. This fund aims to evaluate value for money and cashable cost savings resulting from the funded programs. The U.K. Cabinet Office is partnering with the Blavatnik School of Government at the University of Oxford to provide expert advisory services and capacity building support to local governments through the Government Outcomes Lab (GO Lab) (Cabinet Office, 2016a). Other examples are provided in Table I.

The proposed National Outcomes Fund would take a portfolio approach to risk, funding interventions backed by strong evidence, as well as those that are higher risk but show potential. Permission for failure would be an important feature of this approach. The Fund could allocate some-perhaps 10-20 per cent of its portfolio-to projects with a higher risk of not achieving target outcomes. This would enable the Fund to support harder-to-reach populations and more innovative ideas.

The Fund could be centrally housed within government or at arm's-length. These approaches have different merits. A fund housed internal to government would be more likely to gain the support of government ministries and to be viewed as an alternative service delivery platform and resource for advancing ministry mandates. It would, however, be more likely to suffer from the risk-aversion that is typical to government. An external platform, conversely, would better protect a space for innovation, but face a steeper challenge in maintaining connections to the government bodies upon whom the systemic adoption of effective service delivery approaches depends. This has been the experience of Grand Challenges Canada, a government-funded platform that has been successful in taking a risk-management approach to supporting innovation in global health, but has struggled with building government buy-in (S. Doyle, personal communication, August 19, 2016).

In the near-term, this paper suggests launching a National Outcomes Fund within the Privy Council Office. The risk transfer implicit in an outcomes fund would help to override traditional government accountability structures, providing protection from government risk aversion. In the longer-term, consideration could be given to spinning the Fund out into an arms-length institution, with a broader mandate for social sector research and development, to test new ideas and build a robust innovation pipeline.

Funding for this initiative could be allocated either as "new money" or as a reallocation of a small percentage of program funds from implicated departments-in alignment with the federal government's commitment to dedicate a fixed percentage of program funds to experimenting with new approaches (Liberal Party of Canada, 2016).

The proposed Fund is by no means a silver bullet. Keen attention to design and implementation will be required to realize its intended objectives. Moreover, other initiatives are needed to ensure that new approaches are continuously being developed, tested and scaled. An outcomes fund would play a vital role within a broader policy innovation agenda. By virtue of its unique accountability structure, it would help to stimulate a culture shift in government to bring outcomes into sharper focus.

\section{CONCLUSIONS}

Canada would benefit from a stronger focus on outcomes, to ensure that value is maximized for scarce public resources. With increasing demand for services from an aging population and a shrinking tax base, the need to apply an innovation lens to complex social challenges-to design new approaches, test their ability to realize target outcomes, and scale those that prove effective-is pressing.

A National Outcomes Fund has the potential to transform the lives of less-advantaged Canadians, build evidence on approaches for effectively serving these populations, increase the efficiency of public expenditures, deliver public sector savings, and pave a path towards a social impact economy that appropriately values social outcomes.

\section{ACKNOWLEDGMENTS}

This article was made possible with support from the MaRS Centre for Impact Investing and Saskatchewan Ministry of Justice. Thank you to the many experts who helped to inform this paper. In particular, thank you to Adam Jagelewski and Duncan Farthing-Nichol from the MaRS Centre for Impact Investing for their review and editing support.

\section{CONFLICT OF INTEREST DISCLOSURES}

Dale McFee is the Chair of the CSKA Board, which is the governing body of the Journal. The authors declare there are no other conflicts of interest. The views expressed in the article are solely those of the authors.

\section{AUTHOR AFFILIATIONS}

*MaRS Centre for Impact Investing, Toronto, ON; ${ }^{\dagger}$ Ministry of Justice, Government of Saskatchewan; Regina, SK.

\section{REFERENCES}

Big Lottery Fund. (2016, October 20). Commissioning better outcomes and the Social Outcomes Fund. London, UK: Big Lottery Fund. Retrieved from https://www.biglotteryfund.org.uk/sioutcomesfunds

Cabinet Office, Government of Great Britain. (2013). About commissioning better outcomes and the Social Outcomes Fund. London, UK: Cabinet Office. Retrieved from https://www.gov.uk/government/uploads/ system/uploads/attachment_data/file/261051/CBO_guide.pdf

Cabinet Office, Government of Great Britain. (2016a). Overview of the Life Chances Fund. London, UK: Cabinet Office. Retrieved from: https:// www.gov.uk/search? q=Overview+of+the+Life+Chances+Fund

Cabinet Office, Government of Great Britain. (2016b). The Social Outcomes Fund. London, UK: Cabinet Office. Retrieved from https://data.gov.uk/ sib_knowledge_box/social-outcomes-fund-cabinet-office-uk 
Cabinet Office and Department for Communities and Local Government, Government of Great Britain. (2014a). Fair Chance Fund: Annex C tariff structure, metrics and evidence requirements. London, UK: Cabinet Office. Retrieved from https://www.gov.uk/government/uploads/ system/uploads/attachment_data/file/317399/Annex_C__Metrics_ and_Evidence.pdf

Cabinet Office and Department for Communities and Local Government. (2014b). Fair Chance Fund: Full bid specification documentation. London, UK: Cabinet Office. Retrieved from https://www.gov.uk/ government/uploads/system/uploads/attachment_data/file/529368/ Fair_Chance_Fund_full_bid_specification_archived.

Cabinet Office, Government of Great Britain. (2014c). £23 million to help homeless turn around their lives [Press Release]. (2014, December 9). London, UK. Department for Communities and Local Government, Cabinet Office. Available from: https://www.gov.uk/government/news/23million-to-help-homeless-turn-around-their-lives

Canadian Police College. (2014). Canadian Police College Discussion Paper Series: Change and innovation in Canadian policing. Ottawa, ON:CPC. Retrieved from http://www.cpc-ccp.gc.ca/

Carp, P. (2016, July 25). Welfare in Australia: Coalition to use data analysis to prevent and stop welfare dependency [online version]. The Guardian. Retrieved from https://www.theguardian.com/australia-news/2016/ $\mathrm{jul} / 25 /$ coalition-to-use-data-analysis-to-prevent-and-stop-welfaredependency

Chisholm, D., Sweeny, K., Sheehan, P., Smit, F., Cuiipers, P., \& Saxena, S. (2016). Scaling-up treatment of depression and anxiety: A global return on investment analysis. The Lancet Psychiatry, 3:415-424

Clark, I., \& Lankin, F. (2006). From red tape to clear results: The report of the Independent Blue Ribbon Panel on Grant and Contribution Programs. Ottawa, ON: Treasury Board of Canada Secretariat.

Dear, A., Helbitz, A., Khare, R., Lotan, R., Newman, J., Sims, G. C., Zaroulis, A. (2016). Social Impact Bonds: The early years. London, UK: Social Finance. Retrieved from: http://www.socialfinance.org.uk/wp-content/ uploads/2016/07/SIBs-Early-Years_Social-Finance_2016_Final-003.pdf

Department of Social Services, Government of Australia. (2016).Try, Test, and Learn Fund: 2016 budget. Canberra, Australia: Department of Social Services. Retrieved from https://www.dss.gov.au/sites/default/files/ documents/05_2016/160503___try_test_learn.pdf

Department for Work and Pensions, Government of Great Britain. (2014). The Innovation Fund pilots: qualitative evaluation - early implementation findings. London, UK: Department for Work and Pensions. Retrieved from: https://www.gov.uk/government/publications/innovation-fundpilots-qualitative-evaluation-early-implementation-findings

Gaetz, S., Dej, E., Richter, T., \& Redman, M. (2014). The state of homelessness in Canada: 2014. Toronto, ON: The Homeless Hub Press. Retrieved from http://www.homelesshub.ca

Goering, P., Veldhuizen, S., Watson, A. et al. (2014). National At Home/ Chez Soi Final Report. Calgary, Alberta: Mental Health Commission of Canada. Retrieved from http://www.mentalhealthcommission.ca
HM Government of Great Britain. Innovation Fund key facts. London, UK: Government of Great Britain. Retrieved October 23, 2016, from https:// www.gov.uk/government/uploads/system/uploads/attachment_data/ file/212328/hmg_g8_factsheet.pdf

Liberal Party of Canada. (2016, October 23). Making decisions [policy statement webpage]. Ottawa, ON: Liberal Party of Canada. Retrieved from https://www.liberal.ca/realchange/making-decisions/

Mental Health Commission of Canada. (2013a). Turning the key: Assessing housing and related supports for persons living with mental health problems and illness. Ottawa, ON: Mental Health Commission of Canada. Retrieved from: http://www.mentalhealthcommission.ca/ English/media/3055

Mental Health Commission of Canada. (2013b). Why investing in mental health will contribute to Canada's economic prosperity and to the sustainability of our health care system: Backgrounder - key facts. Ottawa, ON: Mental Health Commission of Canada. Retrieved from: http://www. mentalhealthcommission.ca/English/media/3104

Miguel, A. and Abughannam, S. (2014). Housing First Social Impact Bond feasibility study. Toronto, ON: MaRS Discovery District. Retrieved from: https://www.marsdd.com/mars-library/housing-first-social-impact-bondfeasibility-study/

Munoz, C., and Donovan, S. (2016, April 19). [Web blog post]. Retrieved from https://www.whitehouse.gov/blog/2016/04/19/administrationnearly-doubles-number-pay-success-feasibility-studies

Office of Social Innovation and Civic Participation, Government of the United States. (2016, October 23). Washington, DC: Social Innovation Fund. Retrieved from https://www.nationalservice.gov/programs/socialinnovation-fund

Smetanin, P., Stiff, D., Briante, C., Adair, C. E., Ahmad, S., \& Khan, M. (2011). The life and economic impact of major mental illnesses in Canada: 2011 to 2014. Toronto, ON: RiskAnalytica on behalf of Mental Health Commission of Canada. Retrieved from http://www.mentalhealthcommission.ca

Tan, S., Fraser, A., Glacomantonio, C., Kruithof, K., Sim, M., Lagarde, M., ... \& Mays, N. (2015). An evaluation of Social Impact Bonds in health and social care. London, UK: Policy Innovation Research Unit. Retrieved from: http://www.piru.ac.uk/assets/files/Trailblazer\%20SIBs\%20interim\%20 report\%20March\%202015,\%20for\%20publication\%20on\%20PIRU\%20 siteapril\%20amendedpdf1 1 may.pdf

Treasurer, Government of Australia. (2016a). Budget 2016-17 Part 2: Expense Measures. Canberra, Australia. Retrieved October 20, 2016, from http:// www.budget.gov.au/2016-17/content/bp2/html/bp2_expense-21.htm

Treasurer, Government of Australia. (2016b). Budget 2016-17 Investment approach to welfare. Canberra, Australia. Retrieved October 20, 2016 from http://www.aph.gov.au/About_Parliament/Parliamentary_Departments/Parliamentary_Library/pubs/rp/BudgetReview201617/Investment 